\title{
Pt-Ru Nanoparticles Supported on Carbon Nanotubes as Methanol Fuel Cell Catalysts
}

\author{
Liang Li and Yangchuan Xing ${ }^{1}$ \\ Department of Chemical \& Biological Engineering \\ University of Missouri-Rolla, Rolla, MO 65409
}

${ }^{1}$ Corresponding author: Email: $\underline{x i n g y @ u m r . e d u}$; Tel: 573-341-6772; Fax: 573-341-4377. 
Two more samples of each Pt-Ru electrocatalsyst were synthesized and the electrochemical measurements for the samples were performed with new working electrodes prepared from the electrocatalysts. The results are shown in Figure SI-1 below. It can be see that the reproducibility is good for all three electrocatalysts, S1, S2, and S3.

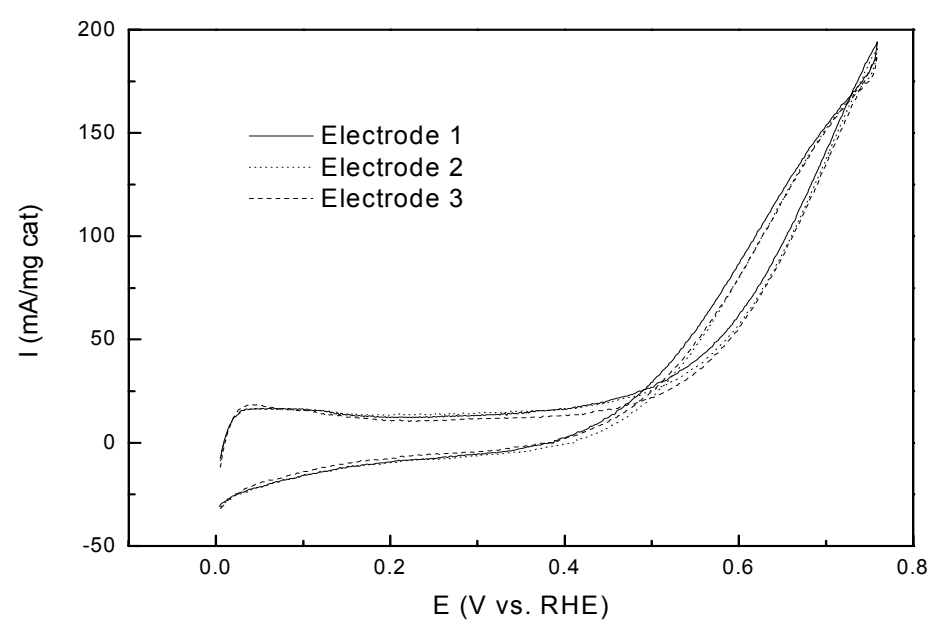

Sample

S 1

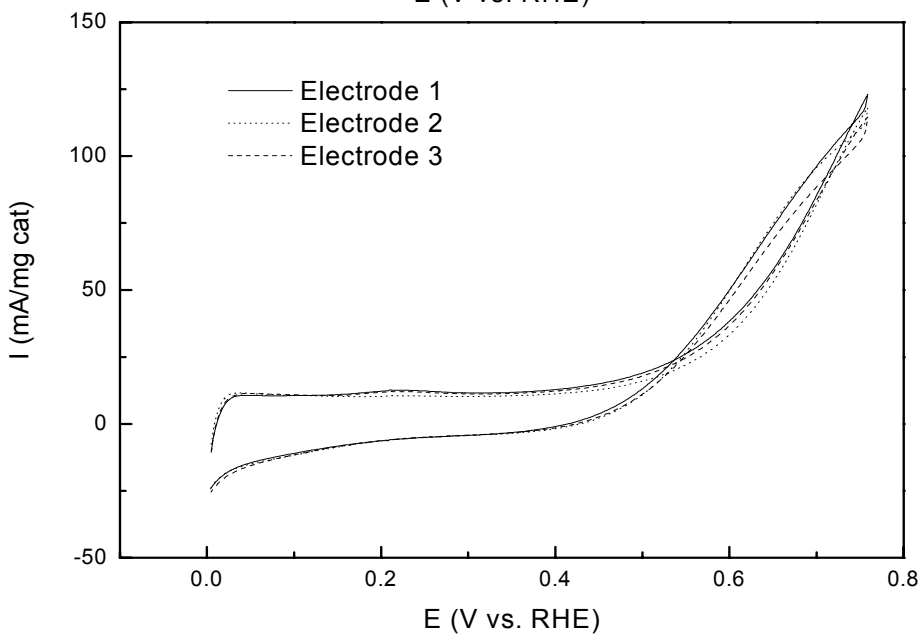

Sample

S2

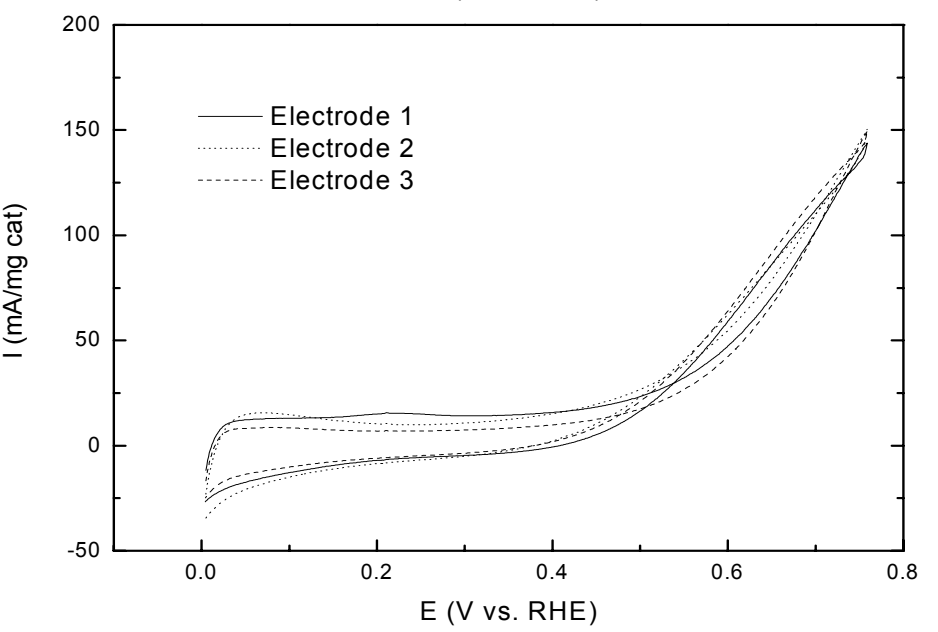

Sample

S3

Figure SI-1 